\title{
The Role of Biogenic Amine Signaling in the Bed Nucleus of the Stria Terminals in Alcohol Abuse
}

\author{
Thomas Louis Kash \\ Bowles Center for Alcohol Studies, Department of Pharmacology, School of Medicine, University \\ of North Carolina Chapel Hill, Chapel Hill, NC, USA
}

\begin{abstract}
There is a growing body of evidence that suggests that stress and anxiety can influence the development of alcohol use disorders. This influence is believed to be due in part to persistent adaptations in discrete brain regions that underlie stress responsivity. One structure that has been proposed to be a site of important neuroadaptations underlying this behavior is the extended amygdala. The extended amygdala is a series of extensively inter-connected limbic structures including the central nucleus of the amygdala $(\mathrm{CeA})$ and the bed nucleus of the stria terminalis (BNST). These structures are critical regulators of behavioral and physiological activation associated with anxiety. Additionally, numerous reports have suggested that these regions are involved in increased drinking behavior associated with chronic alcohol exposure and withdrawal. The focus of this review will be to discuss the role of the BNST in regulation of behavior, to provide some insight in to the circuitry of the BNST, and to discuss the actions of the biogenic amines, serotonin, dopamine and norepinephrine, in the BNST.
\end{abstract}

\section{Microcircuitry of the BNST}

The BNST acts as a critical node in the brain, receiving glutamatergic inputs from cortical, thalamic and amygdalar regions, GABAergic inputs from amygdalar region, and modulatory inputs from brainstem and hypothalamic regions, and then projecting out to many of these same regions (Figure 1). The circuitry in the BNST is complex, perhaps due to the critical role it plays in so many diverse behaviors and processes. Neurons in the BNST are thought to be primarily GABAergic(Sun and Cassell, 1993). These GABAergic BNST neurons express a number of neuropeptides, including CRF, enkephalin, NPY and dynorphin (Kozicz et al., 1997; Walter et al., 1991). Interestingly, CRF and NPY have been shown to have opposing effects on behavior, as NPY is an 'anti-stress' molecule that functionally opposes the actions of CRF (Heilig, 2004; Thiele et al., 2004a; Thiele et al., 2004b). The presence of these neuropeptides in the BNST suggests that there may be neuro-chemically distinct populations of neurons that are differentially engaged by stress or drugs (Day et al., 1999). In addition to this neuro-chemical heterogeneity, individual sub-nuclei have distinct afferent and efferent projections and connectivity within the extended amygdala. While there are many differences, recent reports have suggested that the micro-circuitry of the $\mathrm{CeA}$ can serve as a starting point for understanding the micro-circuitry of the BNST (Figure 2)

\footnotetext{
(C) 2012 Elsevier Inc. All rights reserved.

"Corresponding author: Thomas Kash, Department of Pharmacology and Bowles Center for Alcohol Studies, University of North Carolina Chapel Hill, Chapel Hill, NC 27599, USA, tkash@email.unc.edu, Telephone: 919-966-7116, Fax: 919-966-5678.

Publisher's Disclaimer: This is a PDF file of an unedited manuscript that has been accepted for publication. As a service to our customers we are providing this early version of the manuscript. The manuscript will undergo copyediting, typesetting, and review of the resulting proof before it is published in its final citable form. Please note that during the production process errors may be discovered which could affect the content, and all legal disclaimers that apply to the journal pertain.
} 
(Viviani and Stoop, 2008). Specifically, the medial aspect of the CeA (CeA-M) is the output nucleus, with projections to the brainstem and hypothalamus, while the lateral aspect of the $\mathrm{CeA}$ (CeA-L) functions as an inhibitory projection to the CeA-M (Huber et al., 2005; Savander et al., 1996). This becomes more complicated in the BNST, as there are multiple output nuclei that could be considered analogous to the CeA-M; notably the fusiform nucleus (BNSTfu), a structure located on the ventral edge of the BNST below the anterior commissure and the anterolateral BNST (BNSTal), a structure that surrounds the anterior commissure in both the ventral and dorsal aspects. Anatomical studies show that the neurons in the juxtacapsular nucleus of the BNST (BNSTju) and the oval nucleus of the BNST (BNSTov), subnuclei within the dorsal-lateral BNST, are similar to the CeA-L, with a dense projection to the CeA-M as well as analagous output subnuclei in the BNST (for example the anterolateral BNST) that project to brainstem and hypothalamic nuclei that control behavioral state and neuroendocrine output (Dong et al., 2000). While these nuclei have some common outputs, however, there is a unique pattern of inputs. Notably, there is no projection from the $\mathrm{CeA}$ to the BNSTju, suggesting that GABAergic control of these neurons is regulated primarily by neurons within the BNST(Dong et al., 2000). This stands in contrast with the BNSTov and BNSTal, which receives a dense projection from the CeAL (Dong et al., 2001b). Further, the BNSTju region receives a glutamatergic projection from the basolateral-nucleus of the amygdala, while the BNSTov receives glutamatergic inputs from the insular cortex and the paraventricular thalamus (Dong et al., 2000; Dong et al., 2001b). These differential glutamatergic inputs suggest that there may be critical target dependent plasticity of excitatory transmission that occurs following behavioral manipulations such as alcohol exposure. One of the major challenges in understanding the impact of alcohol and other drugs of abuse on function in the BNST will be to parse out the effects on these different populations of cells and their inputs and outputs.

\section{The BNST as a critical regulator of the stress response/anxiety}

Manipulations of stress and anxiety can shape ethanol related behaviors. The BNST acts as a critical regulator of both stress response and anxiety via a series of projections to the brain stem and hypothalamus (Figure 1). Given that several of these target regions also project to the BNST, it has been proposed that these circuits can form feed forward loops that when engaged, can lead to aberrant behavior. The ability of the BNST to alter the stress response is well characterized. Functionally, lesions of the anterolateral BNST cause significant reductions of corticotrophin releasing factor (CRF) mRNA levels in the PVN (Herman et al., 1994), which results in net reduction in activity of the HPA axis. This effect was specific to the anterolateral portion of the BNST, as lesions of more posterior portions of the BNST increase levels of CRF mRNA in the PVN (Herman et al., 1994). Recent studies from the Sawchenko group have confirmed this important interaction, demonstrating that the anterolateral BNST can integrate information from the medial prefrontal cortex and hippocampal formation and inhibit HPA axis output (Radley and Sawchenko, 2011). The BNST can also play a critical role in regulating anxiety. Microinjection of either $\beta$ - or $a_{1^{-}}$ adrenergic receptor antagonists into the anterolateral BNST attenuates stress-induced reactivity on the elevated plus maze and $a_{1}$-adrenergic receptor agonist alone blocked stress-induced increases in ACTH (Cecchi et al., 2002). Infusion of AMPA receptor antagonists directly in to the BNST can blunt light-enhancement of fear-potentiated startle reflex (Walker and Davis, 1997). Thus the BNST is an integrative point critical for the regulation of anxiety and the HPA axis. 


\section{The BNST plays a key role in modulating rewarding properties of drugs of abuse}

The BNST is heavily inter-connected with 'reward' regions in particular the ventral tegmental area (VTA) (Figure 1) (Dong and Swanson, 2004). In keeping with this, it has been shown that acute exposure to multiple drugs of abuse, including ethanol, leads to increased dopamine levels in the BNST (Carboni et al., 2000). Moreover, several studies have demonstrated that disruption of GABAergic (Hyytia and Koob, 1995) or dopaminergic signaling (Eiler et al., 2003) in the BNST can alter ethanol seeking behavior. Interestingly, results from the Williams' lab showed alterations in GABAergic transmission in the BNST during acute opiate withdrawal (Dumont and Williams, 2004) and an enhancement of the AMPA/NMDA ratio following cocaine self-administration (Dumont et al., 2005), suggestingthat the BNST undergoes adaptations following prolonged drug treatment. Further, work from the Winder group has demonstrated that chronic ethanol and cocaine can alter synaptic function and plasticity in the BNST (Grueter et al., 2006; Healey et al., 2008; Kash et al., 2009; McElligott et al., 2010; McElligott and Winder, 2009). These studies suggest that, in addition to a critical role in anxiety, the BNST is involved in modulating the rewarding properties of drugs of abuse, including ethanol, and is altered following chronic exposure to drugs of abuse. The precise role of these adaptations in the development of addiction-like behavior has not been explored; however, it is tempting to speculate that these drug induced alterations in function are related to the increased involvement of negative reinforcement following chronic drug exposure.

\section{The BNST receives dopamine from the VTA and the A10dc (VIPAG/DR)}

The traditional view of dopamine signaling in the brain has been that dopamine released from cells in the ventral tegmental area (VTA) and substantia nigra (SN) constitutes the virtual entirety of CNS dopaminergic signaling. In addition to this classical dopaminergic afferent, however, the BNST also receives nearly $50 \%$ of its dopaminergic input from the A10dc located in the vlPAG region (Hasue and Shammah-Lagnado, 2002; Meloni et al., 2006). This population of neurons has long been thought to have unusual features relative to SN and VTA neurons, including reduced neurotoxin sensitivity and differential tyrosine hydroxylase (TH) regulation (Xu et al., 1998). Importantly, this population of neurons is not unique to rodents, but is conserved in humans (Saper and Petito, 1982). Little is known of these cells, however recent studies suggest specific roles for A10dc dopaminergic neurons in heroin reward (Flores et al., 2006), opiate regulation of nociception (Flores et al., 2004), and wakefulness (Lu et al., 2006). The ability of drugs of abuse, and more specifically ethanol, and stress to modulate dopaminergic cells in the VTA has been well characterized (Brodie and Appel, 1998; Okamoto et al., 2006). In contrast, the ability of acute ethanol or stress to modulate the dopaminergic cells in the vlPAG, as well as their response to chronic alcohol exposure is currently unknown. While they did not specifically examine dopamine neurons, a recent study demonstrated that swim stress increased expression of the immediate early gene, c-fos, in the vlPAG, raising the possibility that vlPAG DA neurons may be stress responsive. Further, it is unknown if these cells undergo differential neuroadaptations following chronic ethanol exposure. Given that the A10dc dopaminergic neurons project to both the CeA and the BNST, altered transmission in these cells could be an important upstream regulator of CRF function throughout the extended amygdala. An outstanding question remains: what is the role of the A10Dc dopamine cell population of the vlPAG in alcohol abuse? 


\section{BNST Regulation of DA neuron function}

One of the hallmarks of the interactions between the BNST and brainstem structures is a bidirectional interaction, as discussed above in the overview of the anatomy and shown in Figure 1. As such, the BNST receives DA inputs, and can also regulate DA neuron function. Early studies from George and Aston-Jones demonstrated that this was a complicated projection, with both inhibitory and excitatory components (Georges and Aston-Jones, 2001). In expanding this work, they have found that the BNST plays a critical role in prefrontal cortex excitation of VTA DA neurons (Massi et al., 2008). Subsequent studies have suggested that CRF positive neurons project to the VTA; but, it is unclear if these are GABAergic or glutamatergic (Rodaros et al., 2007). It is possible that future studies utilizing optogenetic approaches in genetically modified mice will clarify this circuitry. Unlike the BNST-VTA interaction, there is no published work on the interactions between the BNST and dopamine neurons in the PAG. Several anatomical studies, however, have demonstrated a robust projection from the BNST to the PAG (Dong et al., 2001a; Dong et al., 2001b; Dong and Swanson, 2003, 2004). Indeed, Meloni et al have speculated that the interactions between PAG and BNST are similar to the BNST -VTA interaction, with CRF neurons innervating PAG DA neurons (Meloni et al., 2006).

\section{Dopamine signaling in the BNST}

Drugs of abuse, including ethanol, potently elevate extracellular dopamine in the BNST (Carboni et al., 2000) and that antagonizing D1 receptors within the BNST can reduce alcohol seeking behavior (Eiler et al., 2003). Moreover, in vivo administration of multiple drugs of abuse, including alcohol, engage the MAP kinase (ERK1/2) signaling cascade in BNST neurons in a D1-dopamine receptor antagonist sensitive manner (Valjent et al., 2004). Beyond reward, dopamine signaling in the BNST has been suggested to be involved in regulation of anxiety-like behavior in a potential CRF dependent fashion (Meloni et al., 2006). Interestingly, lesions of the dopaminergic fibers of the medial forebrain bundle caused a reduction in CRF mRNA levels in both the CeA and the BNST (Day et al., 2002). Given that dopaminergic fibers target CRF positive neurons in both the dBNST (Phelix et al., 1994) and the CeA (Hornby and Piekut, 1989), this raises the interesting possibility that dopamine serves to regulate CRF expression in both the dBNST and the CeA. In keeping with the DA CRF interaction, work from the Winder lab found that dopamine lead to a CRFdependent increase in glutamate release in the BNST, providing a mechanism by which dopamine can influence CRF signaling on a circuit scale (Kash et al., 2008). It bears noting that a similar effect was found after $\alpha 1$ and $\beta 1$ adrenergic receptor agonist application (McElligott et al., 2010; Nobis et al., 2011). These data strongly support the idea that there are feed-forward circuits between the BNST and the brainstem cathecholamine centers. In addition, the Dumont group has demonstrated that specifically in the BNSTov dopamine can impair evoked inhibitory transmission via D2 receptor activation, and this modulation was altered following cocaine self-administration (Krawczyk et al., 2011b). Finally, work from the Sanna group has shown that there is a novel form of plasticity in the BNSTju that is D1R dependent (Francesconi et al., 2009a; Francesconi et al., 2009b). Taken together, these results indicate that dopamine can robustly modulate the functional properties of the BNST.

\section{Serotonin involvement in alcoholism}

Studies in alcoholics have demonstrated alterations in markers of 5HT function. Specifically, alcohol-dependent individuals exhibited increases in the 5HT biosynthetic enzyme tryptophan hydroxylase (TPH) in dorsal raphe, the brain stem nucleus that acts as the principle source of serotonin to the brain, including the BNST (Bonkale et al., 2006). Additionally, recent reports have demonstrated alterations in serotonin transporter (SERT) 
density in the amygdala of Type 2, or aggressive, alcoholics (Storvik et al., 2008). Moreover, there is a direct correlation in inbred mice between 5HT clearance and alcohol consumption (Carneiro et al., 2009). Similar results have been obtained in human studies, with individuals with a low-functioning $\mathrm{S}$ allele of the serotonin transporter demonstrating reduced alcohol consumption (Kranzler et al., 2002). It has been proposed that the increased $5 \mathrm{HT}$ tone in individuals with this polymorphism is protective by reducing impulsive behavior, which is strongly correlated with drinking behavior. These studies indicate that the 5HT system is altered in human alcoholics. In addition, 5HT signaling has been implicated in chronic ethanol induced anxiety in animal models (Knapp et al., 2004). Further, ethanol has been shown to modulate expression of 5HT receptors (Pandey et al., 1992). Consistent with these findings, recent reports have demonstrated that $5 \mathrm{HT} 2 \mathrm{C}$ receptors in the amygdala mediate intermittent ethanol exposure-induced increases in anxiety (Overstreet et al., 2006). The role of the $5 \mathrm{HT} 2 \mathrm{C}$ receptor in anxiety is supported by studies using the $5 \mathrm{HT} 2 \mathrm{C}$ knockout mouse (Heisler et al., 2007). Taken together, these studies indicate that the 5HT system is altered following chronic alcohol exposure, and suggest that it represents a potential avenue for therapeutic intervention.

\section{Serotonin signaling in the BNST}

Similar to the amygdala, the BNST receives a 5HT input from the DR (Phelix et al., 1992). Systemic administration of the 5HT2 receptor agonist, mCPP, can activate the BNST, as denoted by an increase in c-fos (Singewald et al., 2003). Recent studies have demonstrated that activation of $5 \mathrm{HT}$ receptors in the BNST can modulate anxiety like behavior. Specifically, a study from the Rainnie group demonstrated that 5HT1A receptor activation in the BNSTal leads to a reduction in anxiety-like behavior (Levita et al., 2004). Conversely, studies from the Hammack lab have shown that mCPP, a 5HT2 agonist, administered in to the BNST leads to increased anxiety-like behavior (Fox et al., 2008), suggesting that 5HT2 receptor activation in the BNST has similar behavioral effects as 5HT2 receptor activation in the amygdala (Cornelio and Nunes-de-Souza, 2007). Using a genetic approach, it was found that in 5HT2C knockout mice there was a deficit in stress induced activation of CRF neurons in the BNST(Heisler et al., 2007). This is particularly interesting given the proposed role of CRF signaling in the BNST(Walker and Davis, 2008) in both anxiety and the negative affective state associated with chronic alcohol exposure. These studies suggest that 5HT1 and 5HT2 receptors in the BNST have opposing actions and differentially regulate anxiety-like behavior. Similar to these differential behavioral effects, $5 \mathrm{HT}$ has a variety of effects on the excitable properties of neurons in the BNST. Specifically, a study from the Rainnie laboratory demonstrated that 5HT can either depolarize, hyperpolarize, or both depolarize and hyperpolarize neurons located in the BNSTal (Levita et al., 2004). A subsequent study identified 5HT1A-induced recruitment of a G-protein coupled potassium channel as responsible for the 5HT-induced hyperpolarization (Levita et al., 2004). A recent study demonstrated that this depolarization was due in part to 5HT2C-Rs (Guo et al., 2009; Hammack et al., 2009). It bears noting, however, that there are also 5HT2A receptors in the BNST which may also play a role in this depolarization. To date, there have been no studies examining the ability of 5HT to modulate inhibitory synaptic function.

Immunohistochemical studies in the 5HT2C-R knockout, however, suggest that 5HT2C-Rs can regulate the activity of CRF neurons in the BNST (Heisler et al., 2007). These studies suggest that 5HT modulates function in the BNST through activation of multiple targets and that alterations of these targets can alter behavior. Further, they suggest that the anxiogenic effects of 5HT2 agonists are mediated, at least in part, by 5HT2C-Rs regulating function in the BNST. This is particularly interesting with regards to alcohol abuse, as 5HT2C antagonist can reduce alcohol withdrawal induced anxiety, suggesting that 5HT2C antagonism may be a viable treatment for anxiety disorders associated with alcohol abuse. 


\section{Norepinephrine Signaling in the BNST: Potential role in Alcohol Abuse}

In addition to dopamine and serotonin, the BNST receives a large noradrenergic input (Egli and Winder, 2003). While early anatomical analysis of these noradrenergic projections suggested that this was predominantly from the nucleus of the solitary tract (NTS) (Forray et al., 2000), recent functional evidence suggested that the locus coeruleus and the NTS can release norepinephrine (NE) in the BNST (Park et al., 2009). Norepinephrine signaling in the BNST has been linked to numerous behavioral outcomes, including activation of the HPA axis, anxiety, stress-induced relapse to drug seeking, and pain (Reviewed in detail by McElligott and Winder (McElligott and Winder, 2009)). Functionally, NE has multiple actions in the BNST. NE can inhibit glutamate release in both ventral and dorsal BNST via activation of a 2 adrenergic receptors (Egli et al., 2005; Krawczyk et al., 2011a). In contrast, NE can enhance glutamatergic transmission in the BNST via both $\beta 1$ and $\beta 2$ adrenergic receptors (Egli et al., 2005; Nobis et al., 2011). Activation of a 1 adrenergic receptors leads to more complex effects on synaptic function and plasticity. Work from the Winder lab has demonstrated that activation of a 1 adrenergic receptors leads to a post-synaptically expressed long-term depression (LTD) (McElligott et al., 2010; McElligott and Winder, 2008), however, it was shown that a 1 adrenergic receptor activation also leads to a CRF-R1 dependent increase in glutamatergic transmission (McElligott et al., 2010). Finally, and perhaps related to the CRF-R1 dependent increase in glutamate, a 1 adrenergic activation can depolarize a subpopulation of neurons in the BNSTal and increase GABA release (Dumont and Williams, 2004). The impact of alcohol exposure on NE modulation of function in the BNST has only been examined for the $a 1$ adrenergic mediated LTD. It was found that four days of alcohol vapor exposure lead to a partial reduction in the magnitude of this LTD. The authors suggested that this was perhaps due to induction of this LTD in vivo (McElligott et al., 2010). This is particularly interesting, as a 1 adrenergic receptor antagonists have shown promise in both preclinical models of alcohol dependence (Rasmussen et al., 2009; Walker and Koob, 2008; Walker et al., 2008) and clinical populations (Simpson et al., 2009). The anatomic localization of this a 1 antagonist mediated effect has not been determined, but given the critical role of the BNST in these actions and the robust noradrenergic input, it is possible that the BNST plays a role.

\section{Summary}

The BNST is a structure that appears to play a critical role in several aspects of alcohol abuse and addiction. The complicated circuitry of this structure provides a fertile ground for discovery, but this same complexity can make it difficult to understand how modulatory systems such as serotonin and dopamine are working on a network level. For example, the GABAergic projection from the $\mathrm{CeA}$ has been thought to play a critical role in alcohol abuse and anxiety. To date, technical limitations have made it difficult to isolate long-range anatomical projections between brain regions of interest such as this pathway. The development of optogenetic approaches combined with novel transgenic animals allows unparalleled means to isolate and measure these pathways in a neurochemically defined fashion. These same approaches can be applied to evaluate the role that specific biogenic amine inputs in to the BNST play in different aspects of alcohol abuse, such as drinking and withdrawal.

\section{References}

Bonkale WL, Turecki G, Austin MC. Increased tryptophan hydroxylase immunoreactivity in the dorsal raphe nucleus of alcohol-dependent, depressed suicide subjects is restricted to the dorsal subnucleus. Synapse. 2006; 60:81-85. [PubMed: 16596624] 
Brodie MS, Appel SB. The effects of ethanol on dopaminergic neurons of the ventral tegmental area studied with intracellular recording in brain slices. Alcohol Clin Exp Res. 1998; 22:236-244. [PubMed: 9514313]

Carboni E, Silvagni A, Rolando MT, Di Chiara G. Stimulation of in vivo dopamine transmission in the bed nucleus of stria terminalis by reinforcing drugs. J Neurosci. 2000; 20:RC102. [PubMed: 11027253]

Carneiro AM, Airey DC, Thompson B, Zhu CB, Lu L, Chesler EJ, Erikson KM, Blakely RD. Functional coding variation in recombinant inbred mouse lines reveals multiple serotonin transporter-associated phenotypes. Proc Natl Acad Sci USA. 2009; 106:2047-2052. [PubMed: 19179283]

Cecchi M, Khoshbouei H, Javors M, Morilak DA. Modulatory effects of norepinephrine in the lateral bed nucleus of the stria terminalis on behavioral and neuroendocrine responses to acute stress. Neuroscience. 2002; 112:13-21. [PubMed: 12044468]

Cornelio AM, Nunes-de-Souza RL. Anxiogenic-like effects of mCPP microinfusions into the amygdala (but not dorsal or ventral hippocampus) in mice exposed to elevated plus-maze. Behav Brain Res. 2007; 178:82-89. [PubMed: 17207863]

Day HE, Curran EJ, Watson SJ Jr, Akil H. Distinct neurochemical populations in the rat central nucleus of the amygdala and bed nucleus of the stria terminalis: evidence for their selective activation by interleukin-1beta. J Comp Neurol. 1999; 413:113-128. [PubMed: 10464374]

Day HE, Vittoz NM, Oates MM, Badiani A, Watson SJ Jr, Robinson TE, Akil H. A 6hydroxydopamine lesion of the mesostriatal dopamine system decreases the expression of corticotropin releasing hormone and neurotensin mRNAs in the amygdala and bed nucleus of the stria terminalis. Brain Res. 2002; 945:151-159. [PubMed: 12126877]

Dong H, Petrovich GD, Swanson LW. Organization of projections from the juxtacapsular nucleus of the BST: a PHAL study in the rat. Brain Res. 2000; 859:1-14. [PubMed: 10720609]

Dong HW, Petrovich GD, Swanson LW. Topography of projections from amygdala to bed nuclei of the stria terminalis. Brain Res Brain Res Rev. 2001a; 38:192-246. [PubMed: 11750933]

Dong HW, Petrovich GD, Watts AG, Swanson LW. Basic organization of projections from the oval and fusiform nuclei of the bed nuclei of the stria terminalis in adult rat brain. J Comp Neurol. 2001b; 436:430-455. [PubMed: 11447588]

Dong HW, Swanson LW. Projections from the rhomboid nucleus of the bed nuclei of the stria terminalis: implications for cerebral hemisphere regulation of ingestive behaviors. J Comp Neurol. 2003; 463:434-472. [PubMed: 12836178]

Dong HW, Swanson LW. Organization of axonal projections from the anterolateral area of the bed nuclei of the stria terminalis. J Comp Neurol. 2004; 468:277-298. [PubMed: 14648685]

Dumont EC, Mark GP, Mader S, Williams JT. Self-administration enhances excitatory synaptic transmission in the bed nucleus of the stria terminalis. Nat Neurosci. 2005

Dumont EC, Williams JT. Noradrenaline triggers GABAA inhibition of bed nucleus of the stria terminalis neurons projecting to the ventral tegmental area. J Neurosci. 2004; 24:8198-8204. [PubMed: 15385602]

Egli RE, Kash TL, Choo K, Savchenko V, Matthews RT, Blakely RD, Winder DG. Norepinephrine modulates glutamatergic transmission in the bed nucleus of the stria terminalis. Neuropsychopharmacology. 2005; 30:657-668. [PubMed: 15602500]

Egli RE, Winder DG. Dorsal and ventral distribution of excitable and synaptic properties of neurons of the bed nucleus of the stria terminalis. J Neurophysiol. 2003; 90:405-414. [PubMed: 12649311]

Eiler WJ 2nd, Seyoum R, Foster KL, Mailey C, June HL. D1 dopamine receptor regulates alcoholmotivated behaviors in the bed nucleus of the stria terminalis in alcohol-preferring $(\mathrm{P})$ rats. Synapse. 2003; 48:45-56. [PubMed: 12557272]

Flores JA, El Banoua F, Galan-Rodriguez B, Fernandez-Espejo E. Opiate anti-nociception is attenuated following lesion of large dopamine neurons of the periaqueductal grey: critical role for D1 (not D2) dopamine receptors. Pain. 2004; 110:205-214. [PubMed: 15275769]

Flores JA, Galan-Rodriguez B, Ramiro-Fuentes S, Fernandez-Espejo E. Role for dopamine neurons of the rostral linear nucleus and periaqueductal gray in the rewarding and sensitizing properties of heroin. Neuropsychopharmacology. 2006; 31:1475-1488. [PubMed: 16292327] 
Forray MI, Gysling K, Andres ME, Bustos G, Araneda S. Medullary noradrenergic neurons projecting to the bed nucleus of the stria terminalis express mRNA for the NMDA-NR1 receptor. Brain Res Bull. 2000; 52:163-169. [PubMed: 10822157]

Fox JH, Hammack SE, Falls WA. Exercise is associated with reduction in the anxiogenic effect of mCPP on acoustic startle. Behav Neurosci. 2008; 122:943-948. [PubMed: 18729648]

Francesconi W, Berton F, Koob GF, Sanna PP. Intrinsic neuronal plasticity in the juxtacapsular nucleus of the bed nuclei of the stria terminalis (jcBNST). Prog Neuropsychopharmacol Biol Psychiatry. 2009a; 33:1347-1355. [PubMed: 19683025]

Francesconi W, Berton F, Repunte-Canonigo V, Hagihara K, Thurbon D, Lekic D, Specio SE, Greenwell TN, Chen SA, Rice KC, et al. Protracted withdrawal from alcohol and drugs of abuse impairs long-term potentiation of intrinsic excitability in the juxtacapsular bed nucleus of the stria terminalis. J Neurosci. 2009b; 29:5389-5401. [PubMed: 19403807]

Georges F, Aston-Jones G. Potent regulation of midbrain dopamine neurons by the bed nucleus of the stria terminalis. J Neurosci. 2001; 21:RC160. [PubMed: 11473131]

Grueter BA, Gosnell HB, Olsen CM, Schramm-Sapyta NL, Nekrasova T, Landreth GE, Winder DG. Extracellular-signal regulated kinase 1-dependent metabotropic glutamate receptor 5-induced long-term depression in the bed nucleus of the stria terminalis is disrupted by cocaine administration. J Neurosci. 2006; 26:3210-3219. [PubMed: 16554472]

Guo JD, Hammack SE, Hazra R, Levita L, Rainnie DG. Bi-directional modulation of bed nucleus of stria terminalis neurons by 5-HT: molecular expression and functional properties of excitatory 5HT receptor subtypes. Neuroscience. 2009; 164:1776-1793. [PubMed: 19778589]

Hammack SE, Guo JD, Hazra R, Dabrowska J, Myers KM, Rainnie DG. The response of neurons in the bed nucleus of the stria terminalis to serotonin: implications for anxiety. Prog Neuropsychopharmacol Biol Psychiatry. 2009; 33:1309-1320. [PubMed: 19467288]

Hasue RH, Shammah-Lagnado SJ. Origin of the dopaminergic innervation of the central extended amygdala and accumbens shell: a combined retrograde tracing and immunohistochemical study in the rat. J Comp Neurol. 2002; 454:15-33. [PubMed: 12410615]

Healey JC, Winder DG, Kash TL. Chronic ethanol exposure leads to divergent control of dopaminergic synapses in distinct target regions. Alcohol. 2008; 42:179-190. [PubMed: 18358675]

Heilig M. The NPY system in stress, anxiety and depression. Neuropeptides. 2004; 38:213-224. [PubMed: 15337373]

Heisler LK, Zhou L, Bajwa P, Hsu J, Tecott LH. Serotonin 5-HT(2C) receptors regulate anxiety-like behavior. Genes Brain Behav. 2007; 6:491-496. [PubMed: 17451451]

Herman JP, Cullinan WE, Watson SJ. Involvement of the bed nucleus of the stria terminalis in tonic regulation of paraventricular hypothalamic CRH and AVP mRNA expression. J Neuroendocrinol. 1994; 6:433-442. [PubMed: 7987374]

Hornby PJ, Piekut DT. Opiocortin and catecholamine input to CRF-immunoreactive neurons in rat forebrain. Peptides. 1989; 10:1139-1146. [PubMed: 2622800]

Huber D, Veinante P, Stoop R. Vasopressin and oxytocin excite distinct neuronal populations in the central amygdala. Science. 2005; 308:245-248. [PubMed: 15821089]

Hyytia P, Koob GF. GABAA receptor antagonism in the extended amygdala decreases ethanol selfadministration in rats. Eur J Pharmacol. 1995; 283:151-159. [PubMed: 7498304]

Kash TL, Baucum AJ 2nd, Conrad KL, Colbran RJ, Winder DG. Alcohol exposure alters NMDAR function in the bed nucleus of the stria terminalis. Neuropsychopharmacology. 2009; 34:2420 2429. [PubMed: 19553918]

Kash TL, Nobis WP, Matthews RT, Winder DG. Dopamine enhances fast excitatory synaptic transmission in the extended amygdala by a CRF-R1-dependent process. J Neurosci. 2008; 28:13856-13865. [PubMed: 19091975]

Knapp DJ, Overstreet DH, Moy SS, Breese GR. SB242084, flumazenil, and CRA1000 block ethanol withdrawal-induced anxiety in rats. Alcohol. 2004; 32:101-111. [PubMed: 15163561]

Kozicz T, Vigh S, Arimura A. Axon terminals containing PACAP- and VIP-immunoreactivity form synapses with CRF-immunoreactive neurons in the dorsolateral division of the bed nucleus of the stria terminalis in the rat. Brain Res. 1997; 767:109-119. [PubMed: 9365022] 
Kranzler H, Lappalainen J, Nellissery M, Gelernter J. Association study of alcoholism subtypes with a functional promoter polymorphism in the serotonin transporter protein gene. Alcohol Clin Exp Res. 2002; 26:1330-1335. [PubMed: 12351926]

Krawczyk M, Georges F, Sharma R, Mason X, Berthet A, Bezard E, Dumont EC. Double-dissociation of the catecholaminergic modulation of synaptic transmission in the oval bed nucleus of the stria terminalis. J Neurophysiol. 2011a; 105:145-153. [PubMed: 21047935]

Krawczyk M, Sharma R, Mason X, Debacker J, Jones AA, Dumont EC. A switch in the neuromodulatory effects of dopamine in the oval bed nucleus of the stria terminalis associated with cocaine self-administration in rats. J Neurosci. 2011b; 31:8928-8935. [PubMed: 21677176]

Levita L, Hammack SE, Mania I, Li XY, Davis M, Rainnie DG. 5-hydroxytryptamine1A-like receptor activation in the bed nucleus of the stria terminalis: electrophysiological and behavioral studies. Neuroscience. 2004; 128:583-596. [PubMed: 15381287]

Lu J, Jhou TC, Saper CB. Identification of wake-active dopaminergic neurons in the ventral periaqueductal gray matter. J Neurosci. 2006; 26:193-202. [PubMed: 16399687]

Massi L, Elezgarai I, Puente N, Reguero L, Grandes P, Manzoni OJ, Georges F. Cannabinoid receptors in the bed nucleus of the stria terminalis control cortical excitation of midbrain dopamine cells in vivo. J Neurosci. 2008; 28:10496-10508. [PubMed: 18923026]

McElligott ZA, Klug JR, Nobis WP, Patel S, Grueter BA, Kash TL, Winder DG. Distinct forms of Gqreceptor-dependent plasticity of excitatory transmission in the BNST are differentially affected by stress. Proc Natl Acad Sci USA. 2010; 107:2271-2276. [PubMed: 20133871]

McElligott ZA, Winder DG. Alpha1-adrenergic receptor-induced heterosynaptic long-term depression in the bed nucleus of the stria terminalis is disrupted in mouse models of affective disorders. Neuropsychopharmacology. 2008; 33:2313-2323. [PubMed: 18046308]

McElligott ZA, Winder DG. Modulation of glutamatergic synaptic transmission in the bed nucleus of the stria terminalis. Prog Neuropsychopharmacol Biol Psychiatry. 2009; 33:1329-1335. [PubMed: 19524008]

Meloni EG, Gerety LP, Knoll AT, Cohen BM, Carlezon WA Jr. Behavioral and anatomical interactions between dopamine and corticotropin-releasing factor in the rat. J Neurosci. 2006; 26:3855-3863. [PubMed: 16597740]

Nobis WP, Kash TL, Silberman Y, Winder DG. beta-Adrenergic receptors enhance excitatory transmission in the bed nucleus of the stria terminalis through a corticotrophin-releasing factor receptor-dependent and cocaine-regulated mechanism. Biol Psychiatry. 2011; 69:1083-1090. [PubMed: 21334600]

Okamoto T, Harnett MT, Morikawa H. Hyperpolarization-activated cation current (Ih) is an ethanol target in midbrain dopamine neurons of mice. J Neurophysiol. 2006; 95:619-626. [PubMed: 16148268]

Overstreet DH, Knapp DJ, Angel RA, Navarro M, Breese GR. Reduction in repeated ethanolwithdrawal-induced anxiety-like behavior by site-selective injections of 5-HT1A and 5-HT2C ligands. Psychopharmacology (Berl). 2006; 187:1-12. [PubMed: 16767411]

Pandey SC, Piano MR, Schwertz DW, Davis JM, Pandey GN. Effect of ethanol administration and withdrawal on serotonin receptor subtypes and receptor-mediated phosphoinositide hydrolysis in rat brain. Alcohol Clin Exp Res. 1992; 16:1110-1116. [PubMed: 1335222]

Park J, Kile BM, Wightman RM. In vivo voltammetric monitoring of norepinephrine release in the rat ventral bed nucleus of the stria terminalis and anteroventral thalamic nucleus. Eur J Neurosci. 2009; 30:2121-2133. [PubMed: 20128849]

Phelix CF, Liposits Z, Paull WK. Monoamine innervation of bed nucleus of stria terminalis: an electron microscopic investigation. Brain Res Bull. 1992; 28:949-965. [PubMed: 1379113]

Phelix CF, Liposits Z, Paull WK. Catecholamine-CRF synaptic interaction in a septal bed nucleus: afferents of neurons in the bed nucleus of the stria terminalis. Brain Res Bull. 1994; 33:109-119. [PubMed: 7903902]

Radley JJ, Sawchenko PE. A common substrate for prefrontal and hippocampal inhibition of the neuroendocrine stress response. J Neurosci. 2011; 31:9683-9695. [PubMed: 21715634] 
Rasmussen DD, Alexander LL, Raskind MA, Froehlich JC. The alpha1-adrenergic receptor antagonist, prazosin, reduces alcohol drinking in alcohol-preferring (P) rats. Alcohol Clin Exp Res. 2009; 33:264-272. [PubMed: 19032582]

Rodaros D, Caruana DA, Amir S, Stewart J. Corticotropin-releasing factor projections from limbic forebrain and paraventricular nucleus of the hypothalamus to the region of the ventral tegmental area. Neuroscience. 2007; 150:8-13. [PubMed: 17961928]

Saper CB, Petito CK. Correspondence of melanin-pigmented neurons in human brain with A1-A14 catecholamine cell groups. Brain. 1982; 105:87-101. [PubMed: 7066676]

Savander V, Go CG, Ledoux JE, Pitkanen A. Intrinsic connections of the rat amygdaloid complex: projections originating in the accessory basal nucleus. J Comp Neurol. 1996; 374:291-313. [PubMed: 8906500]

Simpson TL, Saxon AJ, Meredith CW, Malte CA, McBride B, Ferguson LC, Gross CA, Hart KL, Raskind M. A pilot trial of the alpha-1 adrenergic antagonist, prazosin, for alcohol dependence. Alcohol Clin Exp Res. 2009; 33:255-263. [PubMed: 18945226]

Singewald N, Salchner P, Sharp T. Induction of c-Fos expression in specific areas of the fear circuitry in rat forebrain by anxiogenic drugs. Biol Psychiatry. 2003; 53:275-283. [PubMed: 12586446]

Storvik M, Haukijarvi T, Tupala E, Tiihonen J. Correlation between the SERT binding densities in hypothalamus and amygdala in Cloninger type 1 and 2 alcoholics. Alcohol Alcohol. 2008; 43:2530. [PubMed: 18039673]

Sun N, Cassell MD. Intrinsic GABAergic neurons in the rat central extended amygdala. J Comp Neurol. 1993; 330:381-404. [PubMed: 8385679]

Thiele TE, Naveilhan P, Ernfors P. Assessment of ethanol consumption and water drinking by NPY Y(2) receptor knockout mice. Peptides. 2004a; 25:975-983. [PubMed: 15203244]

Thiele TE, Sparta DR, Hayes DM, Fee JR. A role for neuropeptide Y in neurobiological responses to ethanol and drugs of abuse. Neuropeptides. 2004b; 38:235-243. [PubMed: 15337375]

Valjent E, Pages C, Herve D, Girault JA, Caboche J. Addictive and non-addictive drugs induce distinct and specific patterns of ERK activation in mouse brain. Eur J Neurosci. 2004; 19:1826-1836. [PubMed: 15078556]

Viviani D, Stoop R. Opposite effects of oxytocin and vasopressin on the emotional expression of the fear response. Prog Brain Res. 2008; 170:207-218. [PubMed: 18655884]

Walker BM, Koob GF. Pharmacological evidence for a motivational role of kappa-opioid systems in ethanol dependence. Neuropsychopharmacology. 2008; 33:643-652. [PubMed: 17473837]

Walker BM, Rasmussen DD, Raskind MA, Koob GF. alpha1-noradrenergic receptor antagonism blocks dependence-induced increases in responding for ethanol. Alcohol. 2008; 42:91-97. [PubMed: 18358987]

Walker DL, Davis M. Double dissociation between the involvement of the bed nucleus of the stria terminalis and the central nucleus of the amygdala in startle increases produced by conditioned versus unconditioned fear. J Neurosci. 1997; 17:9375-9383. [PubMed: 9364083]

Walker DL, Davis M. Role of the extended amygdala in short-duration versus sustained fear: a tribute to Dr. Lennart Heimer Brain Struct Funct. 2008; 213:29-42.

Walter A, Mai JK, Lanta L, Gorcs T. Differential distribution of immunohistochemical markers in the bed nucleus of the stria terminalis in the human brain. J Chem Neuroanat. 1991; 4:281-298. [PubMed: 1718318]

Xu ZQ, Lew JY, Harada K, Aman K, Goldstein M, Deutch A, Haycock JW, Hokfelt T. Immunohistochemical studies on phosphorylation of tyrosine hydroxylase in central catecholamine neurons using site- and phosphorylation state-specific antibodies. Neuroscience. 1998; 82:727-738. [PubMed: 9483531] 


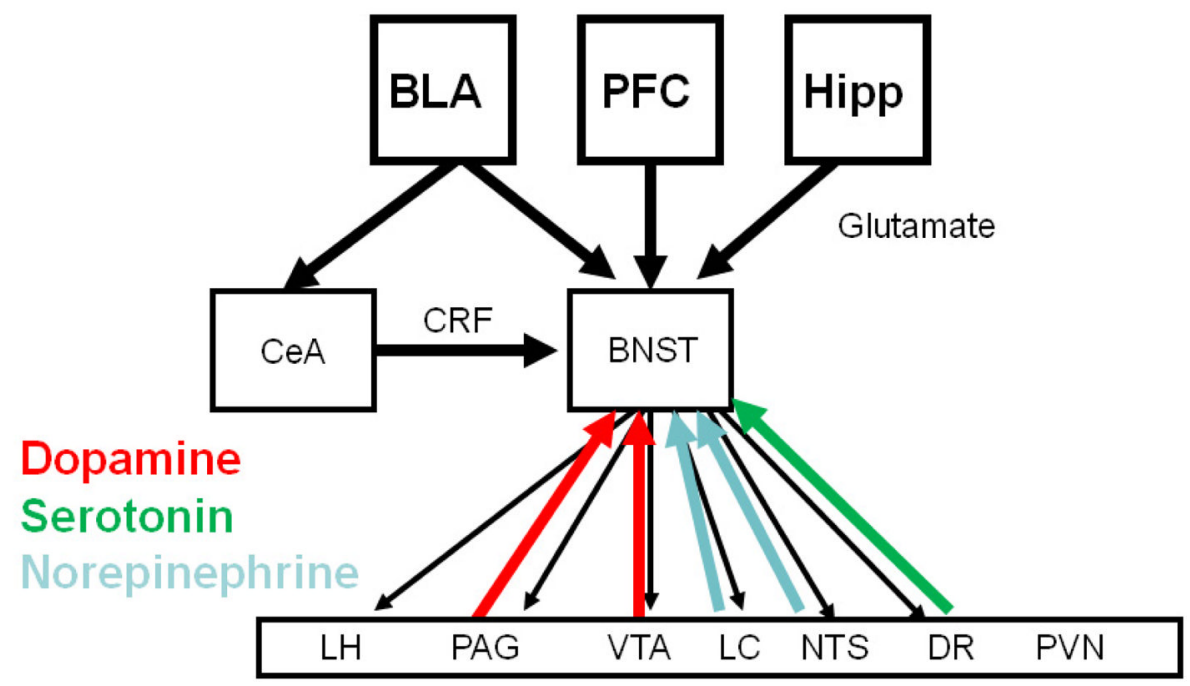

Figure 1.

Network diagram outlining the connectivity of the BNST. The BNST receives glutamatergic projections from the basolateral amygdala (BLA), the prefrontal cortex (PFC) and the hippocampus (Hipp) and a GABAergic/CRF projection from the central nucleus of the amygdala (CeA). The BNST then projects back to the CeA, as well as brain regions that mediate for the specific systemic and behavioral indicators of fear and anxiety. Shown on the diagram are the lateral hypothalamus $(\mathrm{LH})$, periacqueductal grey (PAG), locus coeruleus (LC), nucleus tractus solitaries (NTS), ventral tegmental area (VTA), the paraventricular nucleus of the hypothalamus (PVN) and the dorsal raphe (DR). Several of these brain regions project back to the BNST, suggesting the possibility of feed-back and feed-forward circuits. It should be noted that the CeA also projects to the same targets as the BNST, however it does not project to the PVN. 


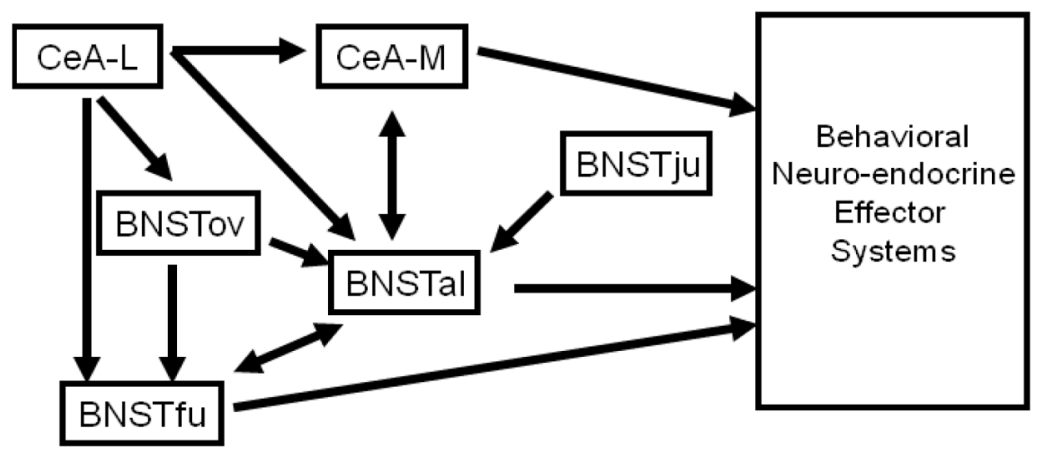

Figure 2.

Diagram outlining the microcircuitry of the anterior BNST, including interactions with the central nucleus of the amygdala (CeA). Importantly, this model highlights the complexity of these interactions. Further, it demonstrates that there are multiple output regions of the BNST, both the fusiform nucleus (BNSTfu) and the anterolater nucleus (BNSTal), that exhibit distinct ouput patterns with some overlap. Further, there are several structures that act as inhibitory nodes on these output nuclei; the oval nucleus (BNSTov) and the juxtacapsular nucleus (BNSTju), the lateral nucleus of the CeA (CeA-L) and the BNSTfu. 